\section{Achalasia associated with two epiphrenic diverticula}

\section{Dear Editor,}

Here, we present the case of a 63-year-old, previously healthy, female patient who sought treatment at a general surgery outpatient clinic complaining of an approximate one-year history of dysphagia for solids. An upper gastrointestinal series showed achalasia and two diverticula in the distal esophagus (Figure 1). Those findings were also documented by computed tomography (Figure 2) and upper gastrointestinal endoscopy. The latter identified an area of esophagitis in one of the diverticula, and that was confirmed by biopsy.

Diverticula that occur in the distal $10 \mathrm{~cm}$ of the esophagus, known as epiphrenic diverticula, can be congenital or acquired. The congenital form, which is extremely rare, results from communication between the esophageal lumen and a duplication cyst. Those are true diverticula, with mucosa, submucosa, a muscle layer, and adventitia. Acquired diverticula are actually pseudodiverticula, formed by herniation of the mucosa and submucosa through the muscle layer. Such herniation is caused by increased pressure in the esophageal lumen. Therefore, acquired diverticula are referred to as traction pseudodiverticula. There are always predisposing conditions, such as collagen diseases, hiatal hernias, and, especially, esophageal motility disorders ${ }^{(1,2)}$.

The best imaging method for the initial approach to esophageal disorders is an upper gastrointestinal series, because it is noninvasive and can demonstrate not only the anatomy but also esophageal motility ${ }^{(1)}$.

Dysphagia for solids, the main complaint of the patient, is a nonspecific symptom and can occur in various esophageal disorders. Many epiphrenic diverticula are asymptomatic or only mildly symptomatic $^{(3)}$. When present, symptoms generally arise from impaired peristalsis. In the case presented here, the symptoms were probably caused by the achalasia. The occurrence of two epiphrenic diverticula in the same patient, as in this case, is rare $e^{(1,4)}$

The retention of residues in diverticula can cause halitosis, regurgitation, aspiration pneumonia, and esophagitis ${ }^{(4)}$. The condition can evolve to metaplasia of the epithelium, which would explain the increased risk of developing esophageal cancer (as occurs in $0.3-3.0 \%$ of cases). Episodes of gastrointestinal bleeding can also occur ${ }^{(3)}$.

\section{REFERENCES}

1. Bruggeman LL, Seaman WB. Epiphrenic diverticula. An analysis of 80 cases. Am J Roentgenol Radium Ther Nucl Med. 1973;119:266-76.

2. Tedesco P, Fisichella PM, Way LW, et al. Cause and treatment of epiphrenic diverticula. Am J Surg. 2005;190:891-4.

3. Conklin JH, Singh D, Katlic MR. Epiphrenic esophageal diverticula:

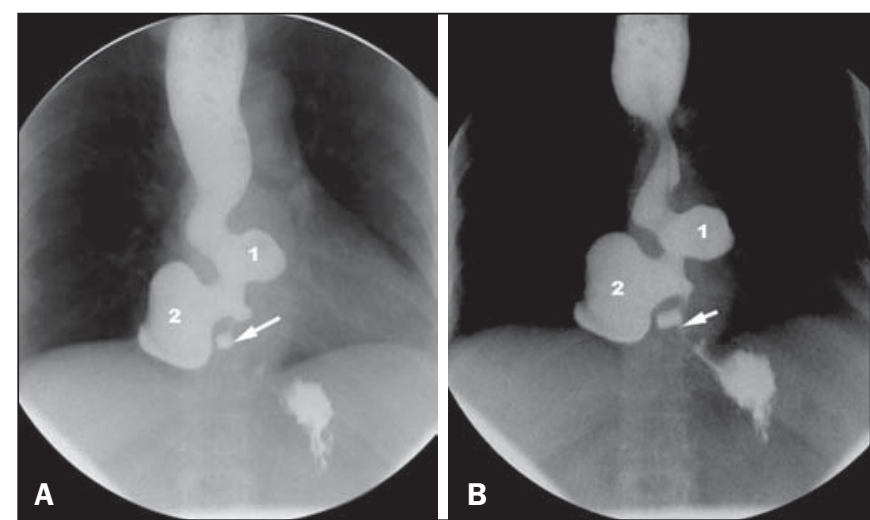

Figure 1. Barium swallow image sequences, obtained with the patient standing, showing narrowing of the lumen and spasm of the distal esophagus, indicating achalasia (arrow). Immediately above, two diverticula can be seen ( 1 and 2). The proximal esophagus is dilated and shows impaired peristalsis.
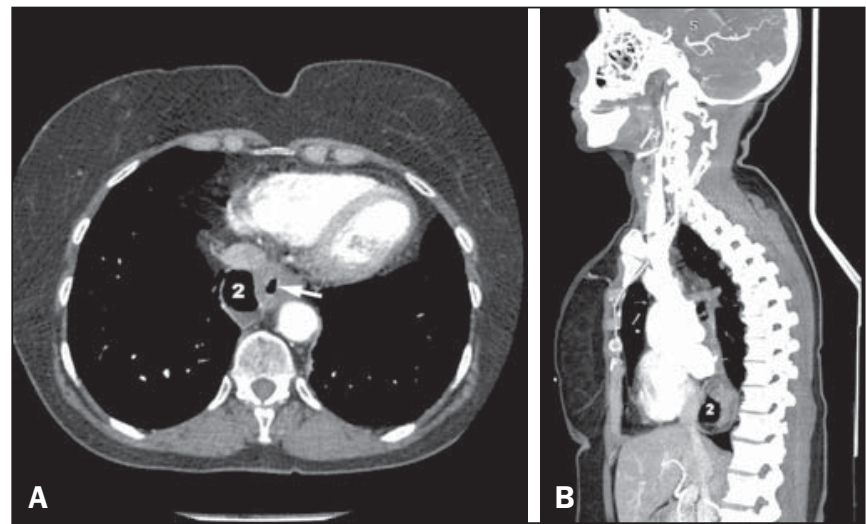

Figure 2. A: Axial CT slice, with a mediastinal window, demonstrating air in diverticulum 2 and in the esophageal lumen (arrow). B: Reformatting in the sagittal plane, showing the posterior position of diverticulum 2 .

spectrum of symptoms and consequences. J Am Osteopath Assoc. 2009; 109:543-5.

4. Fasano NC, Levine MS, Rubesin SE, et al. Epiphrenic diverticulum: clinical and radiographic findings in 27 patients. Dysphagia. 2003;18:9-15.

Stéphano Santos Belisário ${ }^{1}$, Gabriel Antonio de Oliveira $^{1}$, Rodrigo Stênio Moll de Souza ${ }^{1}$, Thais Julio Pacheco ${ }^{1}$, Elton Francisco Pavan Batista ${ }^{1}$

1. Universidade Federal do Espírito Santo (UFES), Vitória, ES, Brazil. Mailing address. Dr. Stéphano Santos Belisário. Avenida Marechal Campos, 1355, Santos Dumont. Vitória, ES, Brazil, 29040-091. E-mail: stephanobelisario@gmail.com.
Foreign body in the bronchus of a child: the importance of making the correct diagnosis

\section{Dear Editor,}

A 7-year-old female presented to the emergency room with a 24-hour history of dyspnea, fever, and an episode of syncope. Physical examination showed an axillary temperature of $38^{\circ} \mathrm{C}$ and absent breath sounds on the left. The blood workup showed a leukocyte count of 21,000 cells $/ \mathrm{mm}^{3}$, with eight rods. Computed tomography (CT) of the chest was performed, after which the patient was admitted with a presumptive diagnosis of pneumonia.
On the first day of hospitalization, the patient showed a decrease in oxygen saturation, cyanosis, and cardiopulmonary arrest, all of which were reversed after routine cardiopulmonary resuscitation maneuvers. After 30 days of antibiotic treatment and intensive care, there was improvement in the clinical and biochemical parameters. Nevertheless, on pulmonary auscultation, breath sounds were still diminished on the left. In view of that finding, another CT scan of the chest was performed.

The first chest CT had shown atelectasis in the left lung (Figure 1A), which was erroneously interpreted as pneumonia. The second CT scan, acquired one month after, showed a diffuse re- 
Figure 1. In A, CT scan of the chest, showing total atelectasis of the left lung. In $\mathbf{B}$ and $\mathbf{C}$, a second CT scan, acquired one month later, showing a diffuse reduction in attenuation in the left lung, with discrete hyperinflation. Note also, in $\mathbf{C}$, the dense image within the left main bronchus (arrows). In $\mathbf{D}$, photograph of the foreign body removed by bronchoscopy.

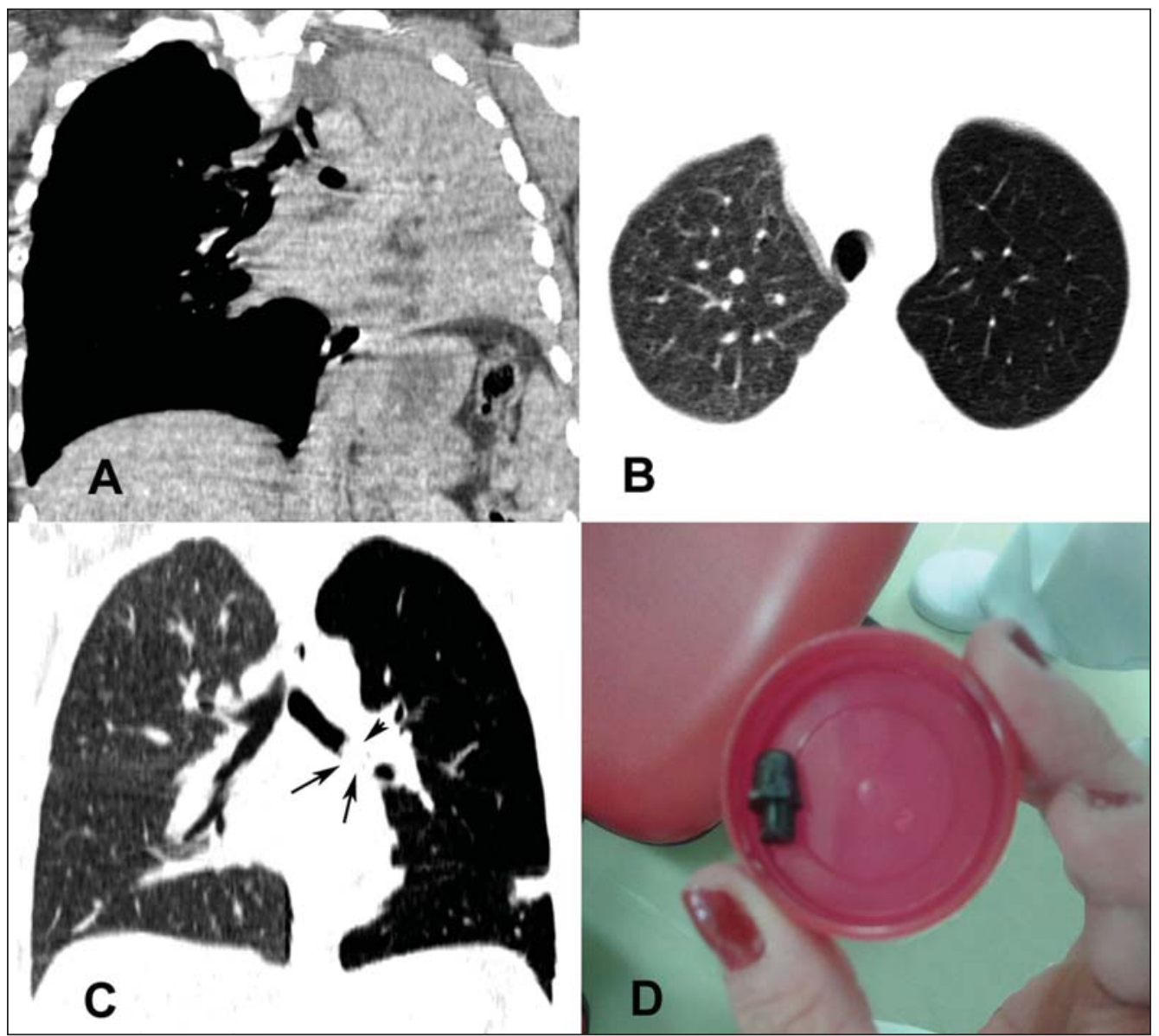

duction in the attenuation of the left lung parenchyma, with hyperinflation (Figures 1B and 1C). The possibility of partial bronchial obstruction was suggested, strengthened by the rounded image observed in the distal third of the left main bronchus, with a diameter of $20 \mathrm{~mm}$. The patient underwent bronchoscopy, and a foreign body (part of a plastic ballpoint pen) was identified and removed (Figure 1D). She was discharged a few days later.

Foreign body aspiration (FBA) is a common event, with significant potential for morbidity and mortality ${ }^{(1-4)}$. Children, particularly males under three years of age, are most often affected $^{(1,5,6)}$.

A diagnosis of FBA is not always easily made, because, in most cases, the parents did not witness the accident and the suspicion must be based on clinical history, physical examination, and complementary diagnostic methods ${ }^{(1)}$. In general, the clinical presentation depends on factors such as the type, size, and location of the foreign body, as well as the age of the patient. It is of note that some victims are asymptomatic and show no alterations on physical examination ${ }^{(1,5,6)}$.

The majority of aspirated foreign bodies are radiolucent, and the image findings on radiographic examinations are, therefore, secondary to their presence in the airway and depend on the size of the foreign body, site of impaction, and degree of obstruction caused $^{(3,5)}$. The main radiological findings are atelectasis, air trapping/pulmonary hyperinflation and identification of a radiopaque foreign body, as well as, less often, pneumomediastinum and pneumothorax $^{(2)}$.

CT is the examination of choice for the evaluation of a large number of lung diseases, as shown in recent studies in the radiol- ogy literature of Brazil ${ }^{(7-12)}$. CT and bronchoscopy are useful in the investigation of cases of persistent respiratory symptoms in which the diagnostic hypothesis is FBA. The diagnosis of the FBA should be made early because a delay in its recognition and treatment can result in definitive sequelae or fatal damage. In many cases, recurrent respiratory diseases are treated for weeks or months before there is suspicion of $\mathrm{FBA}^{(1)}$.

In conclusion, the presence of acute respiratory symptoms accompanied by atelectasis in children should be a signal for the likelihood of FBA, making it an early indication for bronchoscopy, which can be diagnostic as well as therapeutic.

\section{REFERENCES}

1. Fraga AMA, Reis MC, Zambon MP, et al. Foreign body aspiration in children: clinical aspects, radiological aspects and bronchoscopic treatment. J Bras Pneumol. 2008;34:74-82.

2. Mu LC, Sun DQ, He P. Radiological diagnosis of aspirated foreign bodies in children: review of 343 cases. J Laryngol Otol. 1990;104:77882.

3. Hochhegger B, Irion KL, Andrade CF, et al. Congenital lobar emphysema: the role of multislice computed tomography with virtual bronchoscopy in the differential diagnosis with bronchial foreign bodies. Eur Arch Otorhinolaryngol. 2012;269:2015-6.

4. Hochhegger B, Irion KL, Zanetti G, et al. A curious case of pill aspiration. Chest. 2015;147:e234-5.

5. Oliveira CF, Almeida JF, Troster EJ, et al. Complications of tracheobronchial foreign body aspiration in children: report of 5 cases and review of the literature. Rev Hosp Clin Fac Med Sao Paulo. 2002;57:108-11.

6. Bittencourt PFS, Camargos PAM. Aspiração de corpos estranhos. J Pediatr (Rio J). 2002;78:9-18.

7. Franco RM, Guimaraes MD, Moreira BL, et al. Enhancing survival 
with early surgical resection of endobronchial metastasis in a follow-up of ovarian carcinoma. Radiol Bras. 2015;48:130.

8. Barbosa BC, Marchiori E, Zanetti GMR, et al. Catamenial pneumothorax. Radiol Bras. 2015;48:128-9.

9. Francisco FAF, Rodrigues RS, Barreto MM, et al. Can chest high-resolution computed tomography findings diagnose pulmonary alveolar microlithiasis? Radiol Bras. 2015;48:205-10.

10. Batista MN, Barreto MM, Cavaguti RF, et al. Pulmonary artery sarcoma mimicking chronic pulmonary thromboembolism. Radiol Bras. $2015 ; 48: 333-4$.

11. Fernandes GL, Teixeira AA, Antón AGS, et al. Churg-Strauss syndrome: a case report. Radiol Bras. 2014;47:259-61.
12. Nishiyama KH, Falcão EAA, Kay FU, et al. Acute tracheobronchitis caused by Aspergillus: case report and imaging findings. Radiol Bras. $2014 ; 47: 317-9$

\section{Antonio Gabriel de Jesus Barbosa ${ }^{1}$, Diana Penha ${ }^{2}$, Gláucia Zanetti ${ }^{1}$, Edson Marchiori ${ }^{1}$}

1. Universidade Federal do Rio de Janeiro (UFRJ), Rio de Janeiro, RJ, Brazil. 2. Heart and Chest Hospital NHS Foundation Trust, Liverpool, UK. Mailing address: Dr. Edson Marchiori. Rua Thomaz Cameron, 438, Valparaíso. Petrópolis, RJ, Brazil, 25685-120. E-mail: edmarchiori@gmail.com.

http://dx.doi.org/10.1590/0100-3984.2015.0169

\section{Malignant uterine disease with concurrent myometrial contraction at MRI: a possible source of overstaging}

\section{Dear Editor,}

We report a case of a 41-year-old woman with lower abdominal pain and vaginal bleeding with negative ultrasound scan except for fibroids, and elevation of serum $\beta$-hCG $(244,410 \mathrm{mIU} /$ $\mathrm{mL}$ ). Differential diagnoses included ectopic pregnancy, early pregnancy failure, very early ongoing pregnancy and molar pregnancy.

MRI showed an enlarged uterus with central heterogeneous T2 hyperintensity distending the endometrial canal, demonstrating reticular enhancement, concerning for gestational trophoblastic disease. There was also distortion of the junctional zone with broad intermediate-to-low signal on T2-weighted images. The variable appearance of myometrial thickness especially on postcontrast images, showing a homogeneous myometrium, facilitated the diagnosis of contractions (Figure 1). The patient underwent suction and curettage with a final diagnosis of complete hydatidiform mole (HM) (p57 negative).

Gestational trophoblastic disease (GTD) arise from placental trophoblastic tissue after abnormal fertilization and comprises a spectrum of disorders from the pre-malignant conditions of partial $\mathrm{HM}$ and complete HM to the malignant invasive mole, choriocarcinoma and the very rare placental site trophoblastic tumor ${ }^{(1,2)}$. $\mathrm{HM}$ is the most common manifestation of GTD (85\%) and by definition noninvasive and confined to the endometrium. A HM that invades the myometrium is termed invasive mole, and is composed of HM villi within the myometrium. Chorioadenoma
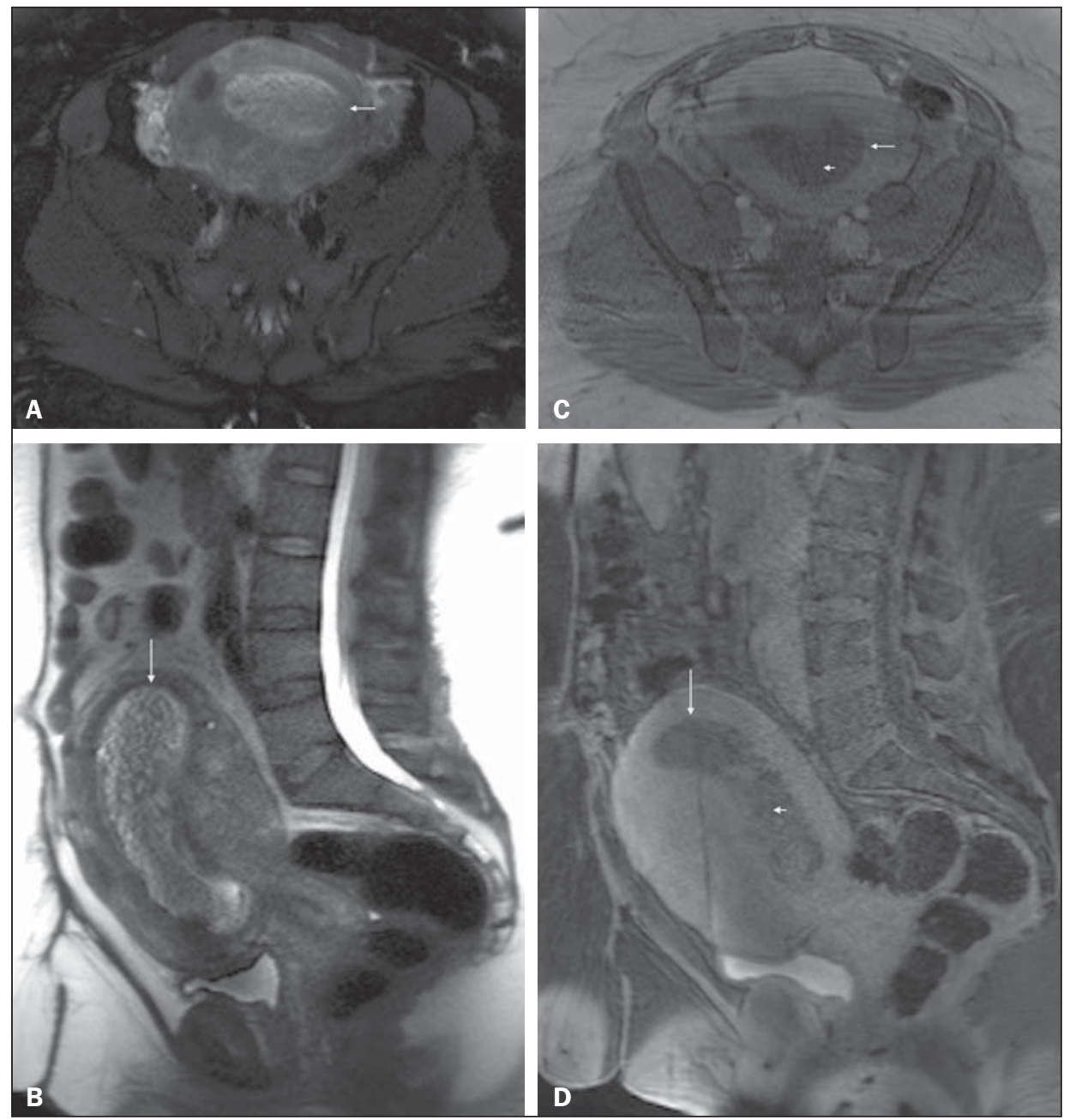

Figure 1. Pelvic MRI. Axial fat-suppressed (A) and sagittal (B) T2-weighted images, and postcontrast axial (C) and sagittal fat-suppressed (D) T1-weighted MRI images. An enlarged uterus is depicted, with a heterogeneous T2-weighted hyperintense lesion distending the endometrial canal (arrows, A-D). The lesion shows reticular enhancement on postcontrast imaging, concerning for gestational trophoblastic disease (short arrows, $\mathbf{C}$ and $\mathbf{D}$ ). Note the different morphologic aspect of the anterior and posterior uterine walls between the first set of images (A and $\mathbf{B}$ ) and those acquired later (C and $\mathbf{D})$, suggesting motion in the context of contraction. These differences are more accentuated on sagittal images, showing substantial increase in thickness and bulging of the posterior myometrial wall on T2-weighted image (B), whereas this pattern is inverted and appearing on the anterior myometrial wall on late post-contrast T1-weighted images (D) (acquired with a delay of $\mathbf{3 0}$ minutes compared to T2-weighted images). 